\title{
Water management at a malted barley brewery
}

\author{
Al van der Merwe and JFC Friend* \\ Environmental Engineering Group, Department of Chemical Engineering, University of Pretoria, Pretoria, South Africa
}

\begin{abstract}
In order to manage and reduce water usage at brewery sites, it is essential that comprehensive water balances be available on which to base informed decisions. During 2001 a water management investigation was completed at a South African brewery to develop a suitable water balance for the plant. Literature studies, plant trials, analysis of historic and current plant data and consultations with brewery personnel were among the diagnostics used in the investigation.

Based on the overall water balance, it was found that $5 \mathrm{~m}^{3}$ of water was used to produce $1 \mathrm{~m}^{3}$ of beer at the brewery. Although the brewery uses lower volumes of water than other sites, numerous opportunities exist to further reduce these volumes. The breakdown of volumes of water consumed and effluent produced per department through the use of a comprehensive water balance, provides an effective tool to manage effluents at brewery sites.
\end{abstract}

\section{Introduction}

The production of beer involves the blending of the extracts of malt, hops and sugar with water, followed by its subsequent fermentation with yeast (Wainwright, 1998). The brewing industry employs a number of batch-type operations in processing raw materials to the final beer product. In the process, large quantities of water are used for the production of beer itself, as well as for washing, cleaning and sterilising of various units after each batch is completed. A large amount of this water is discharged to the drains.

For many years the brewing industry has recorded high ratios of water used to beer produced. This can be as high as 10:1 in sites with a large proportion of smallpack production, and as low as 5:1 on some traditional brewing sites (Crispin, 1996). The main water use areas of a typical brewery are brewhouse, cellars, packaging and general water use. Water use attributed to these areas includes all water used in the product, vessel washing, general washing and cleaning in place (CIP); which are of considerable importance both in terms of water intake and effluent produced.

With rising water prices and ever-increasing competitiveness within the market place, the importance of raw material costs, including water, in determining product costs and profitability should not be ignored. The minimisation of water costs should be given a high priority since it is an area where the consumption (and generation in the case of effluent) is directly under the control of the brewery site (Barnard and Alexander, 1996).

Over the last three decades many papers dealing with all aspects of malt, hops, sugar and yeast can be sourced (Van der Merwe, 2002). However, a review of technical literature related to the brewing industry indicates that little is available on water use and minimisation, in particular the breakdown of water use and effluent generated within relevant departments. The objectives of this investigation were to assess water management at a South African brewery and to determine possible steps that can be introduced to minimise waste volumes and strengths, and hence effluent treatment requirements.

\footnotetext{
* To whom all correspondence should be addressed.

012 420-3741; fax: 012 362-5173; e-mail: ffriend@eng.up.ac.za

Received 4 January 2002; accepted in revised form 11 May 2002.
}

The water balance over each unit process on the brewery site (excluding those associated with malting, which takes place off site) was compiled and the results consolidated into the overall brewery water balance. Information regarding the assessment of water management in the various brewing sections is sourced from literature, plant trials, personal communication and analysis of actual plant data.

\section{Water management at breweries}

There are many unit operations involved in a brewery, all consuming water. A simplified water balance of the water used within a brewery is shown in Fig. 1, whereby the water either becomes part of the beer, part of the effluent or is evaporated. A water ratio is used to describe the total volume of water entering the brewery (A) to the total volume of beer leaving the brewery (B). Ideally the volume of effluent (Stream C) should be minimised which would reduce the costs associated with effluent treatment and purchasing of water (since Stream A would also decrease).

One of the major sources of effluent in a brewing environment emanates from cleaning operations. All vessels and pipelines frequently undergo CIP to ensure that the product is free of undesirable smells and tastes, and fit for human consumption. According to Binnie and Partners (1986), between 65 and $70 \%$ of incoming water forms part of the effluent leaving a brewery. In the past, effluent charges associated with this water, were not very high. However, with the drive towards water conservation in South Africa, higher levies for the discharge and treatment of effluent, as

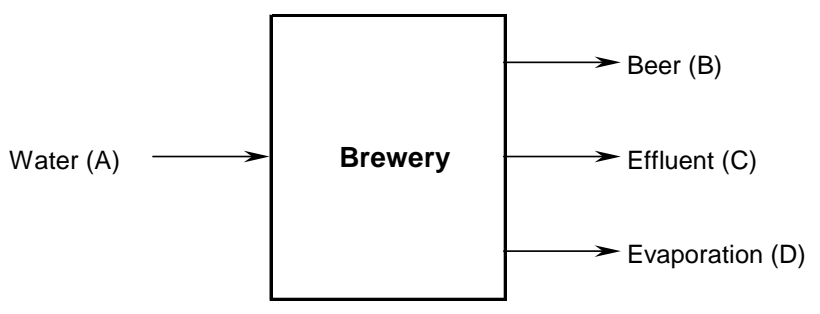

Figure 1

Simplified water balance of a brewery 


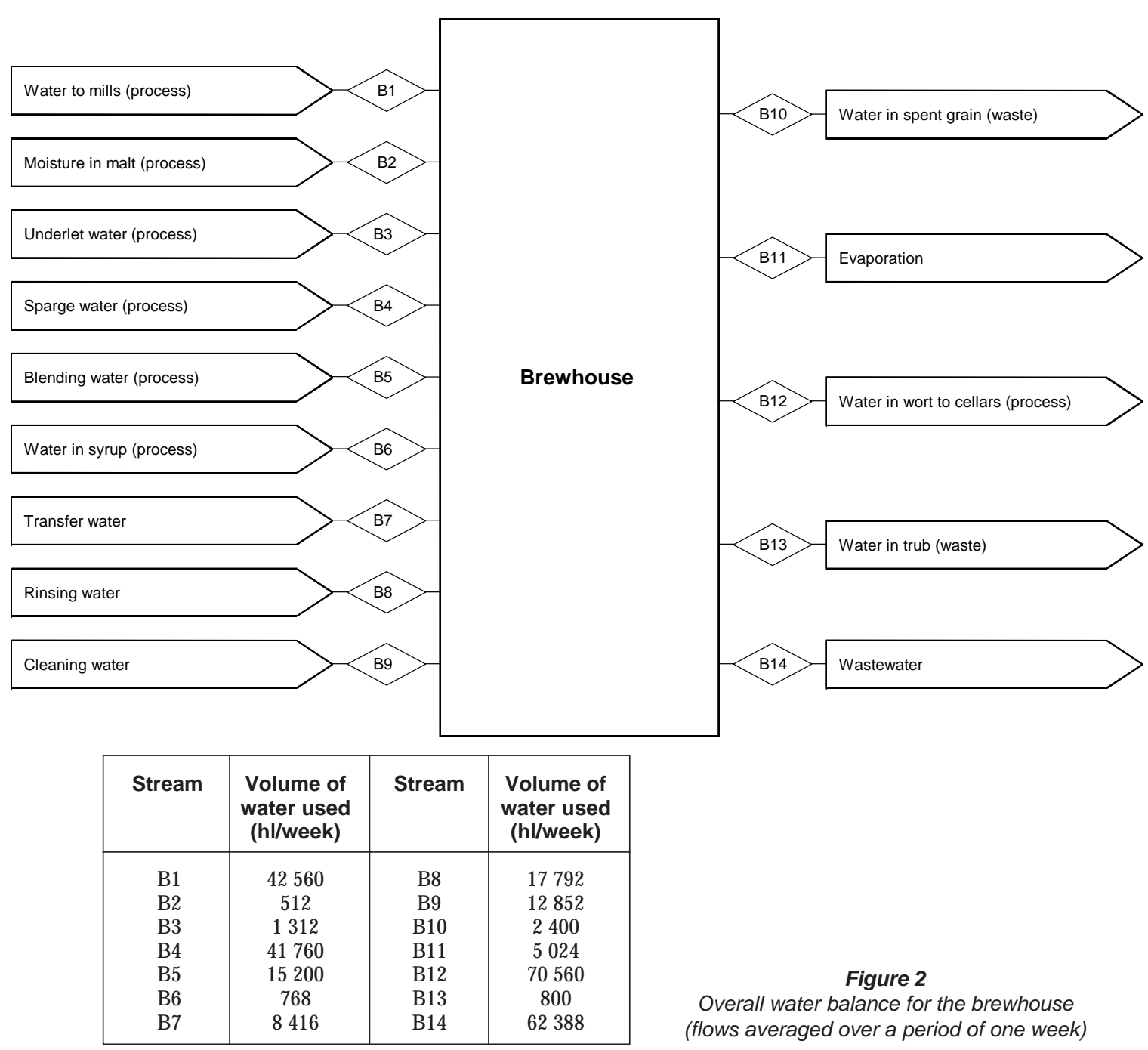

well as higher purchase prices associated with freshwater; are to be expected.

\section{Water balance at a malted barley brewery}

The overall water balance at the relevant brewery includes water used by the brewhouse, the cellars, packaging, general users and CIP stations. Stormwater is not considered as part of the overall water balance as there are no uncovered holding facilities at the plant. All rain-water falling onto the plant, and surrounding areas within the plant's boundary fences, is diverted to storm-water conduits and discharged to the storm-water drains.

In order to compile an effective water balance for the brewery, the water use for all batch and other related processes was converted to averaged volumes over a period of one week and are referenced from Van der Merwe (2002).

\section{Brewhouse}

The overall water balance for the brewhouse is shown in Fig. 2. The brewhouse at the brewery consists of the mills, mash tun, lauter tun, underback, wort kettle, whirlpool and relevant storage vessels (for the addition of hops and syrup). The malted barley (with a moisture content of approximately $4 \%$, or $512 \mathrm{hl}$ of water) is milled to optimise the extraction of soluble substances (for example, starch and proteins) from the malt. The milled malt, now termed grist, exits the milling chamber and is mixed with $42560 \mathrm{hl}$ water at a specified liquor to grist ratio, whereafter it is transferred to the mash tun.

The process of mashing follows and refers to the conversion of barley malt or mash (mixture of grist and water), in the presence of natural enzymes, to a fermentable extract suitable for yeast growth and beer production. The product from the mash tun is transferred to the lauter tun.

In the lauter tun, prior to the transfer of the mash, $1312 \mathrm{hl}$ of water is added in a process called underletting. This water is added to cover the false bottom of the lauter tun to ensure the even distribution of mash in the vessel and therefore facilitates the separation process. After the bulk of the mash liquor has been extracted in the lauter tun, $41760 \mathrm{hl}$ water is sprayed over the bed to recover any remaining liquor. This process is called sparging. The mash liquor recovered in the lauter tun is temporarily stored in a vessel called the underback, before being sent to the wort kettle. In the underback, $15200 \mathrm{hl}$ of blending water is added to the wort. During the transfer from the underback to the wort kettle, syrup or caramel adjunct (containing $22 \%$ or $768 \mathrm{hl}$ water) is added to the mash liquor (adjuncts are substances which provide fermentable sugars in addition to those from the malt). In the wort kettle, this mixture (termed sweet wort) is boiled with hops or hop products during which time approximately $7 \%$ of the volume of product entering the wort kettle is evaporated $(5024 \mathrm{hl}$ of water). The resultant product, termed wort, contains suspended particles derived 


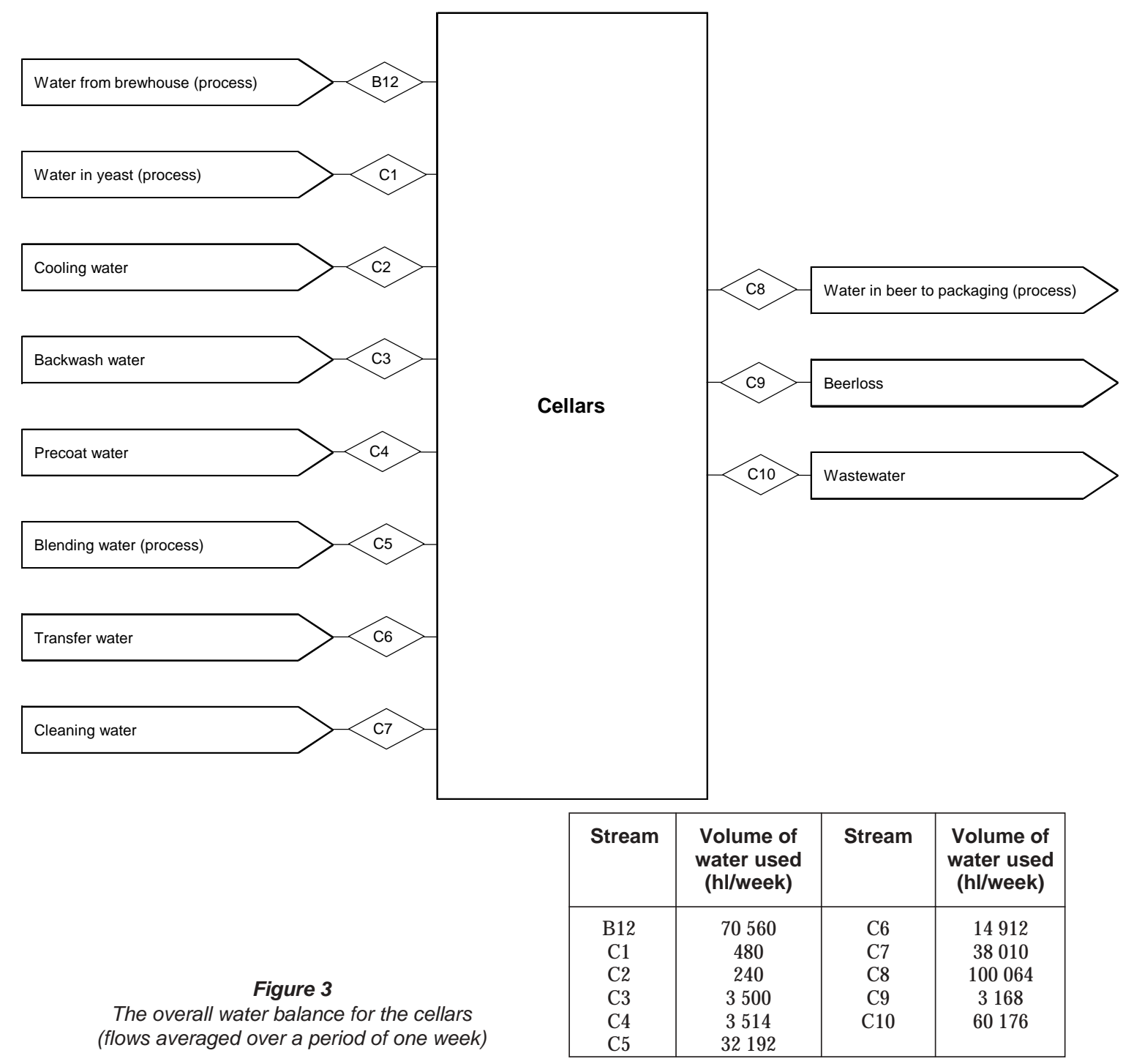

from waste hops material (trub). The trub is separated from the wort in the whirlpool vessels.

In addition, $8416 \mathrm{hl}$ of water is used to transfer the product between vessels, $17792 \mathrm{hl}$ used to rinse the vessels and $12852 \mathrm{hl}$ used to clean the vessels and lines during the CIP cycles. Process water is lost through the disposal of spent grain $(2400 \mathrm{hl})$ and trub $(800 \mathrm{hl})$ by-products, which are sold to farmers as animal feed. From a total of $141172 \mathrm{hl}$ of water used to produce $70560 \mathrm{hl}$ per week of "high gravity" (high concentration of fermentable sugars) wort product, $62388 \mathrm{hl}$ wastewater is discharged from the brewhouse to the drains.

Finally, since $104016 \mathrm{hl}$ of packed beer (with a water concentration of $95 \%$ or $98815 \mathrm{hl}$ ) is produced per week, the ratio of water used to beer packed (a ratio commonly used by the brewing industry to depict water use) can therefore be calculated as (Wainwright, 1998):

Water ratio for the brewhouse $=\frac{141172}{104016}=1.36 \mathrm{hl}$ water/ hl packed beer

The water balance in this section does not include water for washdown and other losses, as these streams will be considered as part of general water.

\section{Cellars}

The overall water balance for the cellars is shown in Fig. 3. The cellar operations include wort cooling, yeast pitching, fermentation, racking, maturation and temporary storage, prior to packaging. During wort cooling, the wort leaving the whirlpool is cooled from approximately $95^{\circ} \mathrm{C}$ to between 9 and $10^{\circ} \mathrm{C}$. The cooled wort is transferred to the fermentation vessels. However, prior to entering the fermentation vessels, aeration of the wort occurs and a batch of yeast is added (or pitched). Approximately $480 \mathrm{hl}$ of water is added to the wort during yeast pitching.

During fermentation organic material is broken down into simpler compounds through the action of micro-organisms (yeast). During the fermentation process, yeast, $\mathrm{CO}_{2}$ (continuously) and trub (not removed in the whirlpool) are removed from the vessels. Approximately $3 \%$ of the beer ( $2144 \mathrm{hl}$ of water) contained within the fermentation vessels, on a volume basis, is lost with the withdrawal of the yeast and trub. At the end of the fermentation process, the product is called green or immature beer.

The transfer of green beer to storage vessels for maturation is referred to as racking (during maturation, green beer flavours are removed by enzymatic reduction of the yeast while in storage). At the brewery the racking process includes centrifugal separation (to remove the yeast), chilling and carbonation steps. To prevent 


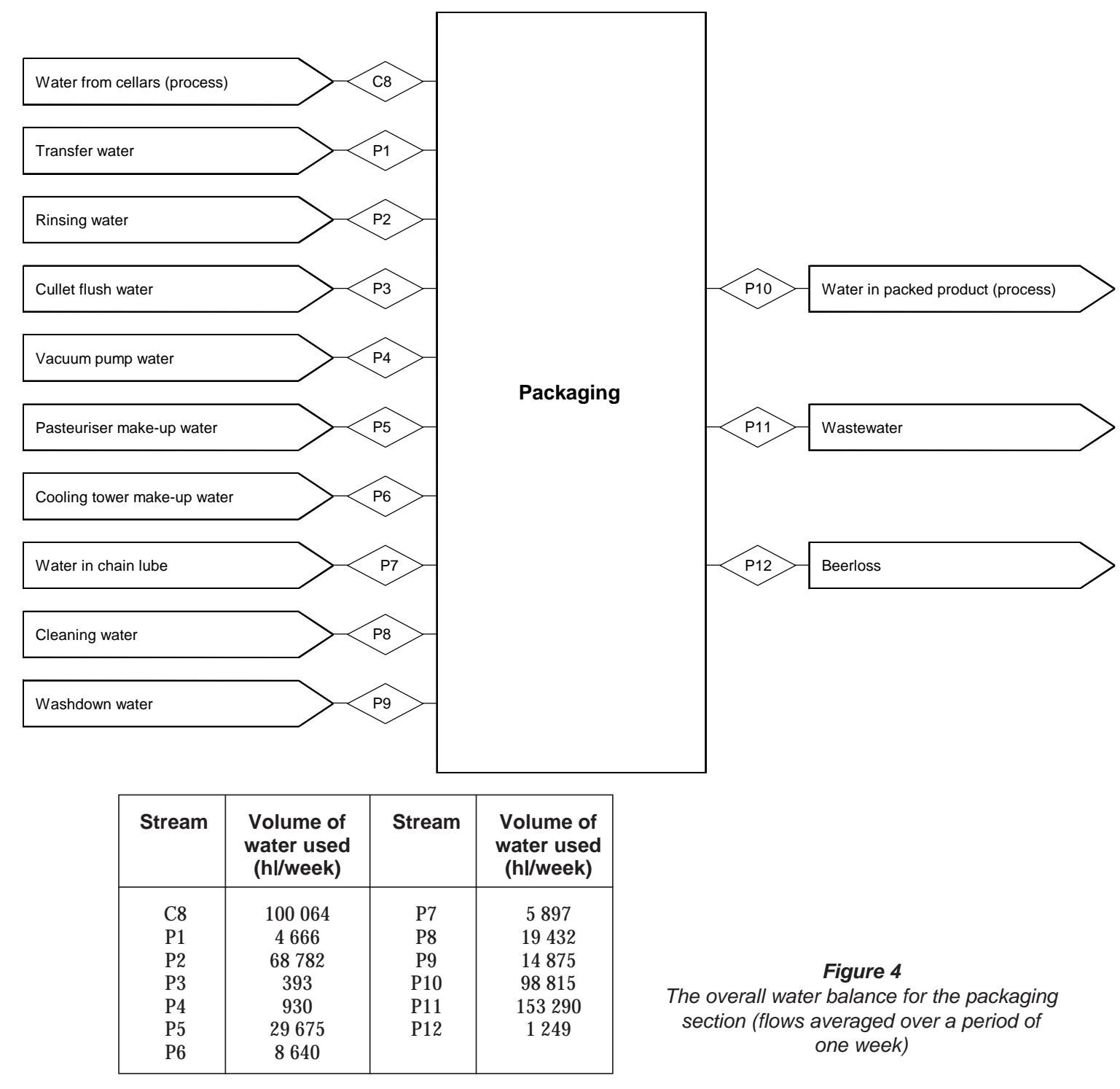

damage to the centrifuge, $240 \mathrm{hl}$ of cooling water is transferred through the shell of the centrifuge and discharged to the drains.

To ensure that all yeast and chill haze (protein residues) are removed from the beer before packaging, the beer undergoes a filtration step. At this particular brewery kieselguhr filter aids are used inside candle filters to form a suitable filter bed during a process called precoating ( $3514 \mathrm{hl}$ of water is used during the precoating process). The spent filter aids are washed out of the filter with $3500 \mathrm{hl}$ of water during backwashing and discharged to the drains. It is estimated that $1.5 \%$ of the beer, on a volume basis (1 $024 \mathrm{hl}$ of water), is lost during filtration. In total $3168 \mathrm{hl}$ of water is discharged to the drains as beer loss.

Since the brewery makes and ferments worts with a relatively high initial extract content, the beer is blended with deaerated carbonated water to the correct alcohol content. After the filtration phase, deaerated carbonated water is added to the beer at a ratio of $0.44 \mathrm{~m}^{3}$ per cubic meter of high-gravity beer (32 $192 \mathrm{hl}$ of water). After the high-gravity beer has been adjusted with deaerated carbonated water, the beer is stored in bright beer tanks (BBT) until a line is planned to pack the beer into relevant containers for distribution and consumption.

In addition, $38010 \mathrm{hl}$ of water is also used for cleaning of vessels and $14912 \mathrm{hl}$ used to transfer the product between vessels and lines. From a total of $92848 \mathrm{hl}$ additional water added into the cellars, $100064 \mathrm{hl}$ of normal-gravity beer is produced and 60176 $\mathrm{hl}$ wastewater discharged to the drains. The ratio for the cellars of $\mathrm{hl}$ water used (additional) to $\mathrm{hl}$ beer packed for the cellars is:

$$
\text { Water ratio for the cellars }=\frac{92848}{104016}=\begin{gathered}
0.89 \mathrm{hl} \text { water/ } \\
\mathrm{hl} \text { packed beer }
\end{gathered}
$$

The water balance in this section does not include water for washdown and other losses, as these streams will be considered as part of general water.

\section{Packaging}

The packaging section at the brewery consists of five production lines of which three are returnable bottle lines (quart lines) and two are non-returnable bottle lines (of which one is a can line and one is a handy line). The overall water balance for the packaging section is shown in Fig. 4.

In the packaging section water is used, inter alia, for the following:

- Filling - $930 \mathrm{hl}$ of water is used by the vacuum pump to create a vacuum required during the filling process and $393 \mathrm{hl}$ of water is used to flush broken glass or cullet from the filler. 


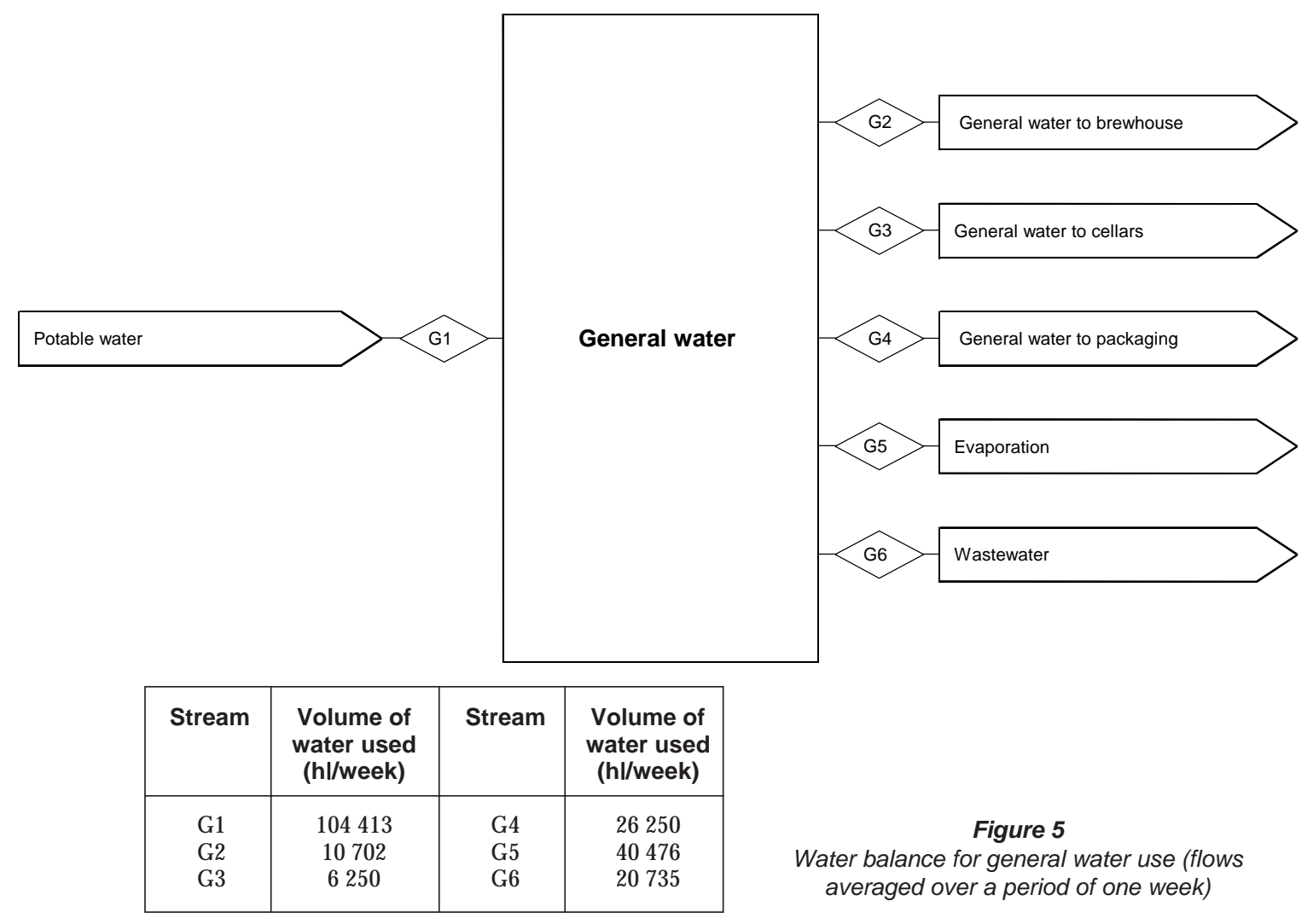

- Pasteurising - $29675 \mathrm{hl}$ of water is used to make-up the levels within the pasteuriser and $8640 \mathrm{hl}$ of water is used for makeup to the cooling towers.

- Chain lube - to reduce friction between the moving parts of the conveyor and between the conveyor and the bottles, a chain lube mixture is added containing $5897 \mathrm{hl}$ of water.

In addition, $68782 \mathrm{hl}$ of water is used for washing and/or rinsing containers and crates, $4666 \mathrm{hl}$ of water is used to transfer the beer to the filler, $19432 \mathrm{hl}$ of water is used for cleaning and $14875 \mathrm{hl}$ of water is used for washdown of equipment. A total of $153290 \mathrm{hl}$ of water is used by the packaging section to pack $104016 \mathrm{hl}$ of beer and the water use ratio for the packaging section is:

Water ratio for the packaging section $=\frac{153290}{104016}=1.47 \mathrm{hl}$ water $/$

The water balance in this section does not include water for washdown and other losses, as these streams will be considered as part of general water.

\section{General water}

The water balance for the general water used in the brewery is shown in Fig. 5. Additional water production/treatment facilities are present to supply the brewery with, inter alia, steam, high temperature water, cold water, cleaning water and drying water (yeast drying). The above is termed general water and in total 104 $413 \mathrm{hl}$ is used to supply $10702 \mathrm{hl}$ to the brewhouse, $6250 \mathrm{hl}$ to the cellars and $26250 \mathrm{hl}$ to the packaging section with $40476 \mathrm{hl}$ lost to evaporation (engine room and boiler house) and $20735 \mathrm{hl}$ discharged to the drains. The water use ratio for general water is:

$$
\text { Water ratio for general water }=\frac{104413}{104016}=\begin{gathered}
1.00 \mathrm{hl} \text { water/ } \\
\mathrm{hl} \text { packed beer }
\end{gathered}
$$

\section{Overall water balance}

The water used in the brewhouse, cellars, packaging and general water was consolidated into an overall water balance. The overall water balance at the brewery is shown in Fig. 6. $491723 \mathrm{hl}$ of water is used to produce $104016 \mathrm{hl}$ of packed beer product per week, resulting in:

$$
\text { Overall water ratio }=\frac{491723}{104016}=4.73 \mathrm{hl} \begin{gathered}
\text { water used } / \\
\mathrm{hl} \text { packed beer }
\end{gathered}
$$

\section{Comparison of water ratios}

The calculated water ratio per section for the brewery, compared to other sites, is shown in Table 1.

\begin{tabular}{|l|c|c|c|}
\hline \multicolumn{4}{|c|}{ TABLE 1 } \\
\hline & Brewery & $\begin{array}{c}\text { Brewery } \\
\text { Site A* }\end{array}$ & $\begin{array}{c}\text { Brewery } \\
\text { Site B** }\end{array}$ \\
\hline & & 1.75 & 1 \\
Brewhouse & 1.36 & 1.15 & 1.09 \\
Cellars & 0.89 & 1.5 & 2 \\
Packaging & 1.47 & 2.25 & 1.95 \\
General water & 1 & 6.65 & 6.28 \\
\hline Total & 4.73 & (1986) \\
\hline * Source : Binnie and Partners (1980) \\
** Source : Pollution Research Group (1987) \\
\hline
\end{tabular}




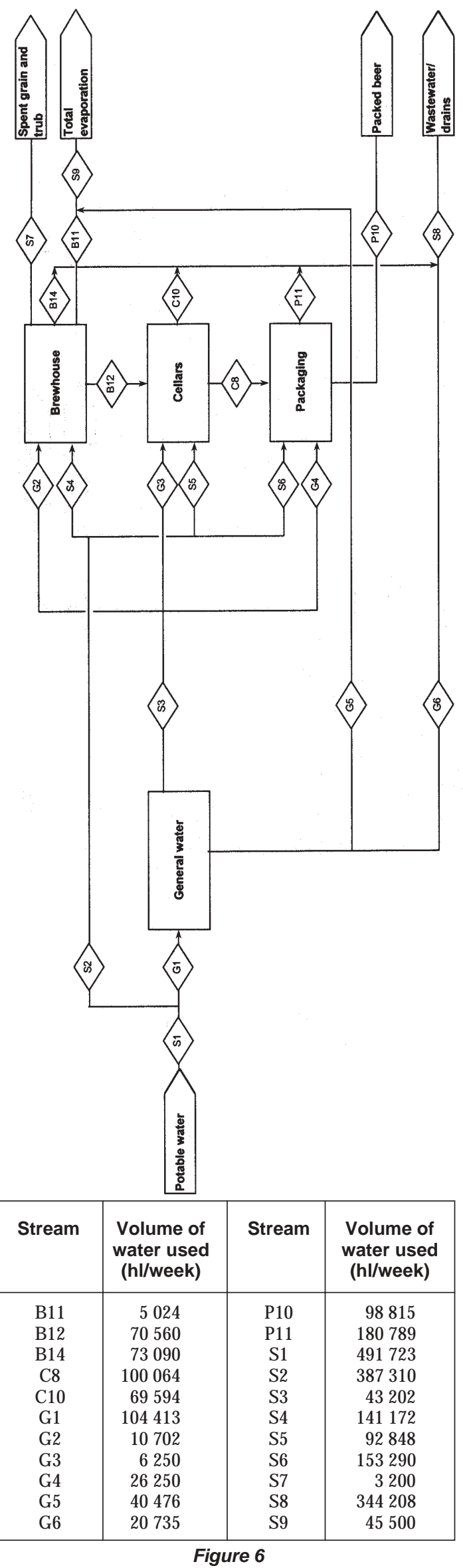

\section{Conclusions and recommendations}

Based on the overall water balance, it was found that approximately $5 \mathrm{~m}^{3}$ of water was used to produce $1 \mathrm{~m}^{3}$ of beer at the brewery. Although water consumption is lower than that reported for other sites, several opportunities remain to minimise the water used within the brewery which would ultimately result in lower effluent volumes and therefore lower effluent costs. These would, however, have to be balanced with relevant product quality issues. Some of the opportunities identified from this investigation to reduce overall water use, which may also be useful to other breweries, are as follows:

- Within the brewhouse, large volumes of water (for example, $39 \%$ of the water entering the lauter tun) are used and released to the drains. Laboratory tests should be conducted to determine the quality of this wastewater at different stages of disposal to the drains, and its reuse capabilities.

- Within the cellars, the timing system used in the transfer process should be analysed and optimised, thus minimising water sent to drains. The possibility to reuse the transfer water for cleaning purposes and the water utilised to precoat the filters as backwashing water should be investigated.

- Within the packaging hall, large volumes of water are used by the three bottle washers for rinsing and discharged to the drains. This water could rather be utilised in the crate washers where the quality of water used plays a lesser role, as the crates do not come into contact with the beer product.

It is recommended that all opportunities to minimise water use in a section should be identified and a centralised water collection area be developed where water with the potential to be reused can be stored. The quality of this water should be analysed and its use for washdown or other purposes investigated, taking due cognisance of product quality.

Finally, the breakdown of volumes of water consumed and effluent produced per department through the use of a comprehensive water balance, will provide an effective tool to manage effluents at brewery sites.

\section{References}

BARNARD R and ALEXANDER JC (1996) Water and Effluent. http:// www.breworld.com (2000, May 1).

BINNIE and PARTNERS (1986) Natsurv 1: Water and Waste-Water Management in the Malt Brewing Industry. Water Research Commission Report TT 29/87, Pretoria.

CRISPIN P (1996) Water, its Supply, Disposal and Conservation. http:// www.breworld.com (2001, May 1).

POLLUTION RESEARCH GROUP (1987) Investigations into Water Management and Effluent Treatment in the Fermentation Industry. Water Research Commission Report 106/3/87, Pretoria.

VAN DER MERWE AI (2002) Water Management at a Barley Brewery. M. Eng. Dissertation, Dept. of Chem. Eng., Univ. of Pretoria, South Africa.

WAINWRIGHT T (1998) Basic Brewing Science. Magicprint (Pty) Ltd., South Africa. 